\title{
ANÓNIMO DE 379: APONTAMENTO ASTROLÓGICO
}

\author{
Reina Marisol Troca Pereira*
}

Recebido em: 11/03/2019

Aprovado em: 11/05/2019
* Professora Auxiliar com Agregação, Departamento de Letras, Universidade da Beira Interior. rmtp@ubi.pt

RESUMO: Este artigo apresenta a tradução portuguesa de um opúsculo astrológico de autoria desconhecida, conhecido como Anónimo de 379. O comentário introdutório aborda os topoi relativos à astronomia e à astrologia na Antiguidade Clássica. Em Tratado sobre as estrelas brilhantes fixas, o astrólogo identifica de que forma os astros determinam temperamentos dos signos do zodíaco, na altura do nascimento, impelindo-os a agir de certo modo.

PALAVRAS-CHAVE: Anónimo de 376; astrologia; astros; signos do zodíaco.

\section{ANONYMOUS OF 379: NOTES ON ASTROLOGY}

\begin{abstract}
This paper presents the Portuguese translation of a booklet on astrology by unknown author, attributed to Anonymous of the Year 379. The initial analysis refers to the topoi of astronomy and astrology in Classical Antiquity. On The Treatise on the Bright-Fixed Stars the astrologer identifies that the planets, the stars, the Sun and the Moon have influence on the character patterns in the birth chart of the signs of the zodiac, impelling them to act in a certain manner.
\end{abstract}

KEYWORDS: Anonymous of the Year 379; astrology; stars; signs of the zodiac. 


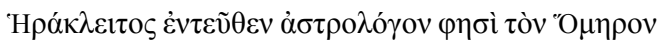

"Heraclito diz que Homero foi astró(logo)(nomo)"

(Heraclito, fr. DK B105)

\begin{abstract}
Auestão ora em apreço sumário radica, desde logo, em dois princípios basilares. $A$ Primeiramente, importa afirmar que a civilização grega, embora haja desenvolvido, $\mathcal{L}$ alargado e apresentado várias ideias acerca da esfera celeste, sol, lua, cinco planetas, ${ }^{1}$ não iniciou a observação e os estudos dos astros, já que estes recebiam menção por egípcios, caldeus, anatólios, babilónios. ${ }^{2}$ Porém, considerar uma divergência absoluta entre duas áreas do mesmo domínio hoje distintas, mas na Antiguidade Clássica não divergentes - astronomia e astrologia ${ }^{3}$ - é erróneo. Assim, há que atender a tal facto nas traduções, pelo que afirmar que o fragmento em epígrafe denota o controverso autor ${ }^{4}$ de Ilíada e Odisseia como um 'astrólogo's seria de certa forma anacrónico.
\end{abstract}

${ }^{1}$ Cf. cinco planetas: Nabu, Isthar, Nergal, Marduk, Ninurta. Ver correspondentes gregos dos deuses
babilónios: Hermes, Afrodite, Ares, Zeus, Cronos; e latinos: Mercúrio, Vénus, Marte, Júpiter, Saturno.
Considere-se, outrossim, a adaptação das constelações babilónicas pelos Gregos, sobretudo a partir do séc. V a. C. (e.g. sumério Gugalana | Touro).

${ }^{2}$ Ver Nikula (1993); Brown (2000).

${ }^{3}$ Vd. Lindsay (1971); Barton (1994).

${ }^{4}$ Cf. a(s) complexa(s) 'questão(-ões) homérica(s)', como conjunto de dúvidas quanto à autoria, datação (ver Hdt. 2.53, estimando Homero e Hesíodo c. 400 anos antes de si), forma de composição das obras, existência factual de alguns conteúdos respeitantes a Homero, a quem desde a Antiguidade se atribuíam os poemas épicos Ilíada e Odisseia. Tais incertezas não pareciam colocar-se na Antiguidade. Contudo, desde os quesitos levantados pelo neoplatónico Porfírio (séc. III), estudiosos adeptos da posição dos analíticos, sucedânea de F. Wolf (séc. XVIII), contrariados pelos unitários muito posteriormente, formulam algumas questões, desde logo, sobre a recensão pisistrátea (cf. Pl. Hipparch. 228 b6-c1; Cic. de Orat. 3.137). Ver Morris - Powell (1997); Nagy (1996). As epopeias atribuídas a Homero contam-se no âmbito da cosmologia rudimentar apresentada na antiguidade pela civilização Grega, que procura explicações físicas racionais de fenómenos celestes, aproveitando autoridades precedentes para desenvolver conhecimentos, instrumentos, artefactos e mecanismos na área.

${ }^{5}$ Em termos gerais, os astros visíveis eram utilizados para orientação (Od. 5.271-7) e para fins oraculares (Od. 20.350-5). Cf. alusão a elementos como estrelas e constelações, a exemplo de Boōtes (cf. Arat. Phaen. 68-9), Orion (Il. 18.485, 489), Ursa Maior, Híades e Plêiades (Od. 5.272-7), Sírio (ominosa estrela do outono, Il. 5.1-5, 22.25-31), Canis Maior, 'Cão Maior' (Il. 22.25-31), Hesperus, 'Estrela da Tarde', Il. 22.317-321) e Eosphorus, 'Estrela da Manhã' (Il. 23.226), correspondendo ambas a Vénus. No respeitante à configuração da plana Terra, emanada do Oceano (cf. arquétipo, Il. 14.200, 245-6), juntamente com Tétis, encimada e equilibrada (Od. 1.53-4) pelo cuproso (Il. 2.458, 16.364, 19.351,

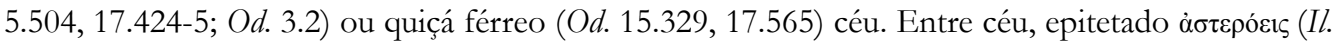
6.108, 15.371) e Terra, ar denso (Il. 14.288), éter (Il. 8.554-559), Olimpo (Od. 1.68-9, 6.242-5). Ao

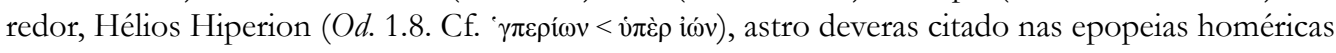
(Il. - 42 vezes; $O d$. - 77 vezes); lua (apenas 3 vezes no poema iliádico e uma ocasião enquanto Mene, $I l$. 19.374; por duas vezes na epopeia odisseica). No respeitante a movimentações astrais e consequências, 


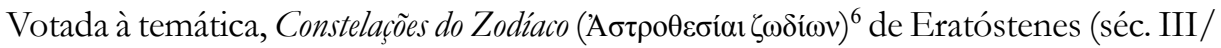
II a.C.) ${ }^{7}$ abordaria, quiçá, na versão original, as constelações (46?) identificadas no séc. IV a. C. Contempla, no Epílogo remanescente, topoi iconográficos, mitológicos (cf. narração inicial, em cada episódio), astronómicos (descrição da constelação), i.e. tradição, à primeira vista ficcional, religiosa, didática e etiológica (correspondendo ao gosto alexandrinista), e racionalidade científica. O opúsculo pseudoeratosténico restante traduz-se como exercício literário de correspondência da iconicidade do firmamento a metáforas, com didatismo etiológico fundamentado na mitologia tradicional e religiosidade. Unem-se por elos de credibilização aspetos de um empirismo simbólico, qual tentativa de aproximação do desconhecido a realidades usuais, nem sempre fornecida e nunca explicada, relativa à luminosidade desses corpos celestes. Prosa descritiva simples, breve e condensada, utilizando a primeira pessoa do plural (plural majestático), denuncia, para além de outros topoi, um percurso de ascensão, não propriamente evolutivo, pois não se ilustra a progressão anímica, mas são colocadas no espaço formas, figuras inanimadas, de certa forma materializando Ar. Pax 832-3, mediante o qual os mortos se tornam estrelas (à $\left.\alpha \tau \varepsilon_{\rho} \varepsilon \varsigma\right)$. Nessa lógica de ensinamento constante e evidente não se vislumbram medições, premonições nem tampouco distâncias, movimentos, reflexões sobre diferentes tipos de astros nem quaisquer outras reflexões astronómicas. Ou seja, a grande distância de estudos posteriores (ex. Arato, Eudoxo, Hiparco de Niceia, Ptolomeu).

importa considerar, na Odisseia, solstícios, e também o eclipse solar total (Od. 20.356-7), quiçá o de 16 de abril de 1178 a.C., marcando a data do assassinato dos pretendentes de Penélope, o que situaria a queda de Troia 10 anos antes. Todavia, tal exegese poderá ser falaz, porquanto provavelmente apenas a imagem metafórica transmitida por Teoclimeno, no retrato de um autor que poderia ter assistido a um fenómeno similar mais proximamente do que $c .4$ séculos antes. A resistência e as numerosas reservas sociais espelham o contraste entre racionalidade/prudência e superstição, ilustrado em episódios como o eclipse solar que suspende o confronto bélico entre Lídios e Medos, a 28 de maio de 585 a.C., julgando por Hdt. 1.74, 7.37. Outrossim, embora filósofos como Anaxágoras de Clazómenas tivessem anteriormente apresentado uma explicação científica e racional dos eclipses, a superstição e o medo do líder ateniense (Nícias) impediu-o de retirar as tropas atenienses antes de consultar os profetas (Tuc. 7.85-86). Sobre o conflito ciência vs. religião, veja-se Pl. Ap. 26d, onde Sócrates-personagem alega adorar, como os restantes Atenienses, o sol.

${ }^{6}$ Obra de autoria incerta, atribuída ao autodenominado filólogo do séc. III/II a.C., Eratóstenes de Cirene (cf. Suet. Gram. 10). Homem de saber e saberes múltiplos, afirmou-se como músico,

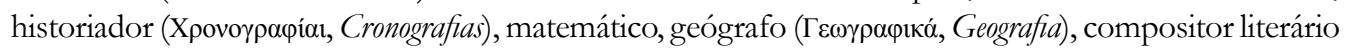

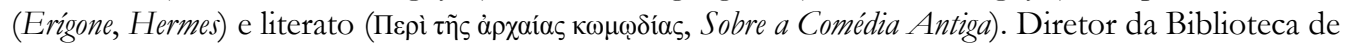

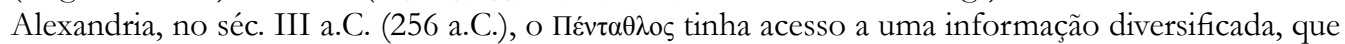

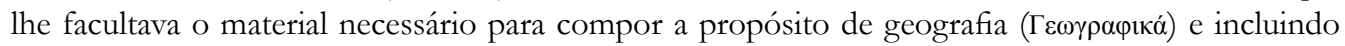

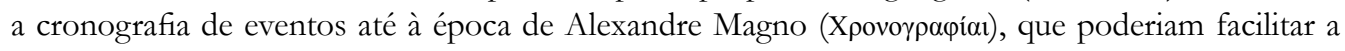

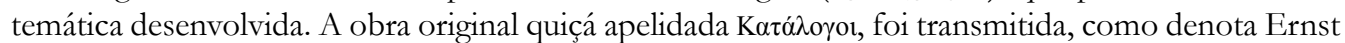
Maass (1883), Analecta Eratosthenica, Berlin, Weidmannsche Buchhandlung: 3, ora sem título, ora sob

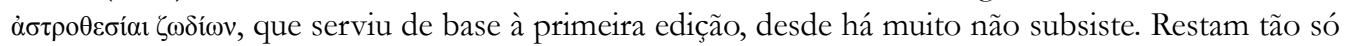
fragmentos e reformulações breves e parciais coligidos tardiamente na forma de um Epitome.

${ }^{7}$ Ver Pérez Jiménez (1994); Pàmias I Massana, Zucker (2013). 
Contudo, urgia igualmente ponderar acerca do poder e influência (quiçá determinismo) das luzes posicionadas no alto sobre as criaturas no plano inferior. ${ }^{8}$ Convergem assim diversos saberes e profissões, a exemplo de religião e sacerdócio, mitologia e etnografia, astronomia, filosofia, geometria, matemática, física natural, sem delimitação estanque e absoluta dos diferentes domínios científicos, designadamente 'astronomia', um dos ramos da matemática (juntamente com aritmética e música), bem como "astrologia" (enquanto arte mágica de procrastinação da sorte e do destino, com base na influência das posições de corpos celestiais sobre criaturas terrenas). Assim, a astrologia parte de conhecimentos astronómicos para desenvolver os seus propósitos (cf. Ptolomeu, Tetrabiblos I.2, ed. Robbins, 1964, p. 10-11).

Regularmente consignado ao anonimato, o apontamento astrológico $\operatorname{tardio}^{10} \mathrm{de}$ que se apresenta seguidamente tradução (Tratado sobre as estrelas brilhantes fixas) revela escrita simples e carácter repetitivo. O libelo é de autoria controversa, ${ }^{11}$ ainda que no decurso do texto possa deduzir-se uma eventual origem egípcia. De facto, referências textuais, como

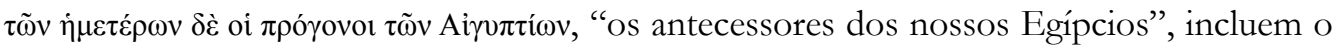
autor entre os Egípcios. Conjuga-se nesse sentido a alusão a entidades egípcias, a exemplo de Hermes Trismegisto (c. $1^{\circ} / 2^{\circ}$ milénio a.C.). Outrossim, contribui de certo modo para tanto a menção de divindades egípcias, designadamente Anúbis, Ísis. O texto encontra-se na obra do Pontífice egípcio do séc. VI, Retorico e recuperado em Teófilo de Edessa. Os Excerpta Parisina, ${ }^{12}$ séc. IX (ano 884), recordam dois fragmentos do astrólogo do ano 379,

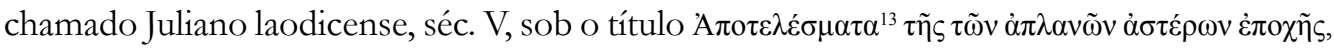
"Determinações da posição das estrelas fixas". ${ }^{14}$ A presente tradução do opúsculo astrológico segue os fólios 135-137 (este último copiado por "outra mão", séc. XV, à semelhança dos ff. 138-148) da primeira publicação do texto, por Franz Cumont e Franz Boll (1904), Catalogus Codicum Astrologorum Graecorum. Partem Priorem, Bruxellis: in Aedibus Heinrich Lamertin: 196-211.

A obra foi redigida em Roma, ${ }^{15}$ decorria o ano de 379 a.C., em século de reflorescimento de estudos astrológicos alexandrinos, no consulado de (Quinto Clódio Hermogeniano) Olíbrio e (Décimo Magno) Ausónio, conforme indica o autor. Tal permite a datação comumente atribuída de 379, no poder imperial de Graciano. Assume uma lógica

\footnotetext{
${ }^{8}$ Ver Allen (1963).

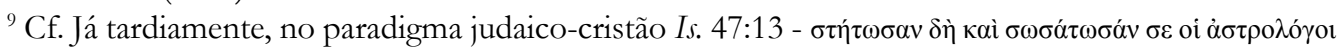

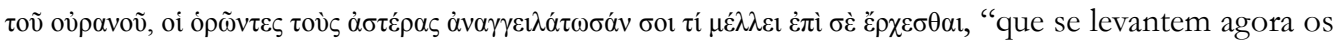
astrólogos, os observadores de estrelas, que fazem previsões mensais e te salvem do que há de vir sobre ti”.

${ }^{10}$ Ver Hand (1993).

${ }^{11}$ Cf. Paulo de Alexandria, segundo Cumont, hipótese rejeitada por Pingree, Schmidt. Juliano de Laodiceia conforme fonte do séc. IX rejeitada por Schmidt.

${ }^{12}$ Cf. Codex Parisinus 2506 (P), séc. XIV e do Codex marcianus 335, séc. XV.

${ }^{13}$ Cf. Mediolanensis. Ver $\left.\tau \dot{\imath} \lambda \varepsilon \sigma \mu \alpha \tau \alpha\right]$ Codex Angelicus.

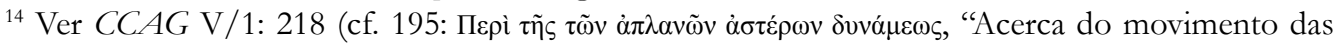
estrelas fixas”). Cf. astrologia e adivinhação, Bouché-Leclercq (1899).

${ }^{15}$ Localidade assumida com a justificação de não referir Canopo por não se erguer nessa latitude.
} 
determinista do posicionamento de certos astros sobre os humanos, condicionando atitude, moral, comportamentos desde a nascença, sobrepondo-se, ao que tudo indica, aos materiais genéticos e ao poder da educação, ainda que sem grandes explanações além de alusões ao levante, ocaso, culminação, pontos basilares, ângulo, dois grupos de estrelas (zodiacais e extra-zodiacais), correlações planetárias, conjugação com a lua. Para além da observação, o autor menciona diversos nomes influentes para o seu trabalho, com particular relevância

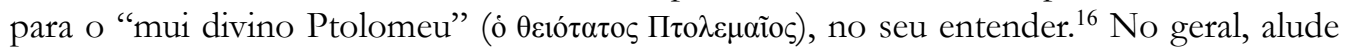
a antecessores, fornecendo um périplo didático, desde Babilónios, Caldeus (viz. Berosso), Egípcios (viz. Hermes, Necao, Cerasforo, Petosiris, Necepsi, Timeu, Asclácio, Antíoco, Valens, Antígono, Heraico, Serápio, Ptolomeu). Meton, Apolinário, Euctémon, Dositeu, Calipo, Filipo, Fócis, Hiparco. Pese embora o objetivo passasse por estabelecer o significado astrológico de 30 estrelas fixas brilhantes, ${ }^{17}$ o texto restante contempla apenas 29. Cada estrela é uma mistura/combinação de dois planetas. ${ }^{18}$

O escrito ora em apreço, com pormenores da influência das estrelas fixas na astrologia natal, revelar-se-ia importante para autores árabes; Teófilo de Edessa (séc. VIII), Abú Ma’shar (séc. IX); 'Palco' / (séc. XIV). ${ }^{19}$

\section{Anónimo de 379, Tratado sobre as estrelas brilhantes fiXas}

\section{F. $135^{\mathrm{v}}$. DETERMINAÇÕES DA POSIÇÃO DAS ESTRELAS FIXAS}

Ora, caso encontres, num nascimento, que a Lua ${ }^{20}$ está a ficar a par das estrelas brilhantes e distintas, o que significa que tem o mesmo número de graus que elas, e

\footnotetext{
${ }^{16}$ Cf. Tetr. 3.15. Ver Newton (1978).

${ }^{17}$ Ver Vaticanus Graecus 208, f. 130v.

${ }^{18}$ Ver no céu, sol, lua, cinco planetas. Cf. Parisinus Graecus 1310: Fenonte (de Cronos. Cf. qaívw:

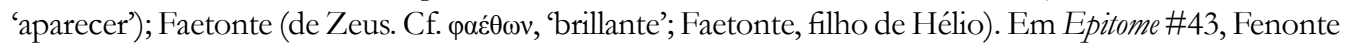
também é o primeiro planeta, mas pertence a Zeus. Platão (Epin. 987b-c) mostra correspondência de

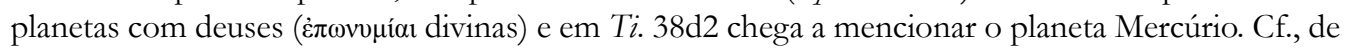
igual forma, epítetos atribuídos a corpos celestes, em obras literárias (ex. Eudox. Ars; posteriormente,

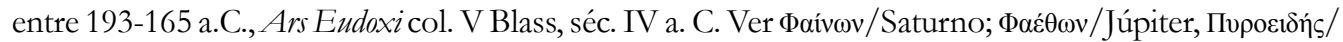

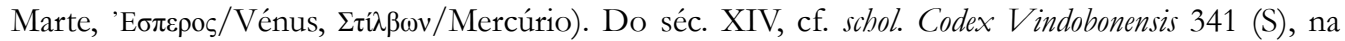

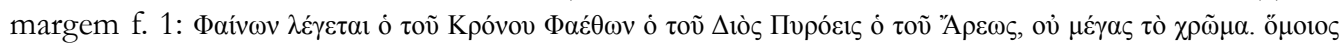

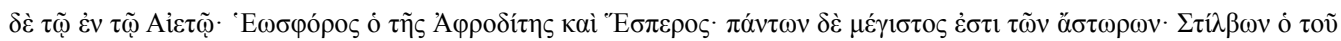

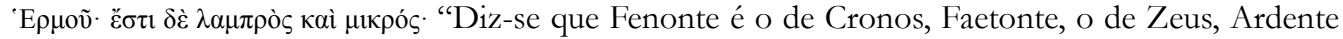
[Marte], o de Ares, não grande, de cor similar à de Águia; Estrela da Manhã e Estrela da Tarde, o de Afrodite, é o maior de todas as estrelas. Lanterna [Mercúrio], o de Hermes. É luminoso e pequeno.” ${ }^{19}$ Quiçá pseudónimo usado por Eleutério Zebeleno de Élis, escriba e astrólogo bizantino do século XIV.

${ }^{20}$ Cf. Selene. Acerca do carácter religioso manifestado na associação dos astros celestes a deuses, ver Eratóstenes, Cat. 43, aludindo a Fenonte (de Cronos. Cf. paivw: 'aparecer'); Faetonte (de Zeus. Cf. paś $\theta \omega v$, 'brillante'; Faetonte, filho de Hélio). Vd. Codex Parisinus Graecus 1310; schol. Codex Vindobonensis 341. Ver Bezza (2002).
} 
principalmente se a Lua se mover rapidamente conforme o vento, ${ }^{21}$ tal como a estrela brilhante que está na proximidade dos graus dela [da Lua], suscitam os melhores, mais brilhantes, mais notáveis e mais favorecidos nascimentos. E similarmente, se uma das estrelas brilhantes marcar a hora da criação ou surgir na hora do nascimento, ou caso se encontre de novo no meio do céu, ou se encontre nos outros pontos básicos, ${ }^{22}$ isto irá produzir aqueles que são estimados, efetivos, dominantes, ocupados em muitos assuntos, com muitas posses, conhecidos ou temidos nas cidades ou regiões, sobretudo naquelas zonas sobre as quais também as estrelas brilhantes se encontram suspensas, ou estão a surgir no momento em que alguém nasce, conforme está registado no catálogo. Quando estão a marcar ou a culminar no meio do céu a hora de nascimento, dão prosperidade desde uma jovem idade e nas suas próprias cidades. Porém, se alguma das estrelas brilhantes se encontrar no ponto do ocaso aquando da hora do nascimento, suscitará prosperidade particularmente no exterior e por volta da meia idade, e concederá um matrimónio radiante, bem como ricas propriedades diferentes devido sobretudo a figuras femininas. Se alguma das estrelas brilhantes se encontrar no ponto básico subterrâneo na hora favorável ao nascimento, traz prosperidade na velhice e felicidade para o nascido e prosperam a partir de grandes propriedades - com efeito, o lugar é invisível -, as mortes deles notáveis e muito reconhecidas. De facto, a partir desse lugar, também entendemos que o corpo nasce depois da morte, ${ }^{23}$ e falamos deles relativamente a um destino honroso. Ora, geralmente, todos os homens que tenham nascido no levante de uma estrela brilhante, ou então quando está num ponto básico, e a Lua, conforme referimos anteriormente, está a colocar-se ao lado de uma estrela brilhante e notável na hora favorável ao nascimento, terá uma brilhante e admirável vida.

A atividade natural delas ${ }^{24}$ é muito grande, admirável e variada e produzem feitos diferentes consoante a mudança dos lugares, sendo necessário expor as observações que os predecessores realizaram a respeito do temperamento peculiar delas. Na realidade, segundo ele, ${ }^{25}$ cada estrela não-errante possui uma relação de proximidade com os planetas e com as misturas deles um temperamento similar. Cada uma consegue e completa essas coisas

\footnotetext{
${ }^{21}$ Entenda-se 'latitude’ ('declínio’?).

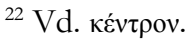

${ }^{23}$ Cf. topos do 'renascimento' evocado a partir da memória e lembrança da ỏpstí ('virtude') decorrente

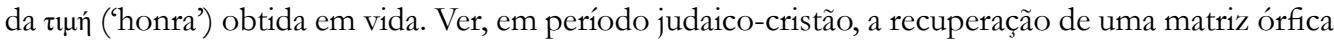
e princípios dualistas, de certa forma inscritos no neoplatonismo, donde a imortalidade da alma (Pl.

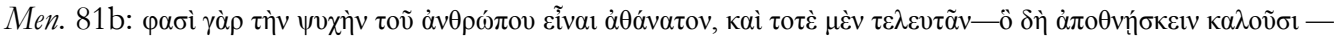

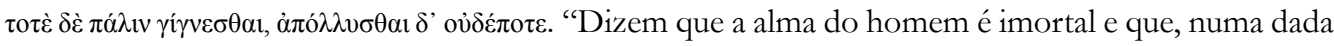
altura, chega ao seu fim, o que é chamado de morte, e noutra nasce novamente, mas nunca morre.”), divinizando-se até certo ponto/sublimando-se o homem ao entender-se a morte como uma mudança de espaço e condição (qual 'metamorfose') rumo a uma verdadeira existência destituída das constrições e dos desejos do vil e efémero corpo.

${ }^{24}$ [estrelas].

25 [temperamento peculiar].
} 
para os planetas, segundo refere o próprio compilador. ${ }^{26}$ De facto, não é necessário considerar apenas a mistura das 5 estrelas e do Sol e da Lua entre si, mas também relativamente àquelas [misturas] das [estrelas] não-errantes que possuem essa natureza. As considerações conduzem-se em conformidade com as familiaridades referidas e registadas no códice, porquanto as suas qualidades são capazes e fazem essas coisas. E assim, encontramos esta ${ }^{27}$ relativamente às estrelas não errantes, entre poucos antigos, e particularmente entre os que filosofam acerca desta parte da previsão e da ciência divina dos números. Alguns entre os antigos que expuseram o conhecimento e a qualidade dos fenômenos de um modo mais disperso e obscuro. Nós, pretendendo preservar a memória daqueles que são dignos das estrelas, retirámos da astronomia tanto quanto de útil Ptolomeu definiu, na arte astronómica. E elaborámos e compusemos primeiramente essa tabela mais recente e inteligível, que mostra toda a sapiência e conhecimento dos fenómenos celestes, assim: ***

De modo a não nublar a claridade da tabela ao usarmos verbosidade, no restante começamos a estabelecer os efeitos relacionados com o poder ativo de cada uma das estrelas não-errantes, depois de inscrever na tabela o grau de longitude ocupado por cada uma delas no consulado de Olíbrio e Ausónio - através do facto de as estrelas não-errantes se moverem 1 grau em 100 anos para as partes que seguem os equinócios e solstícios, tal como o divino Ptolomeu demonstrou -, na altura em que nós escrevemos o livro. E que temperamento cada uma delas tem, e o tipo de latitude ou de direção que expusemos de acordo com o que ele transmitiu, para que nada seja negligenciado na exposição da tabela. ${ }^{28}$ Vamos passar para a ilustração da tabela. Porém, falta iniciarmos a orientação da tabela.

Aqueles homens que nascem no levante de Espiga, a estrela brilhante que está na mão esquerda de Virgem, que está no $29^{\circ}$ grau de Virgem, no próprio zodíaco; ou também quando a [estrela] brilhante de Lira, que emerge com o $20^{\circ}$ grau de Sagitário, ou quando a brilhante que está na boca do Grande Peixe e está na parte sul ${ }^{29}$ se eleva no $10^{\circ}$ grau de Aquário; ou ainda se a brilhante de Cisne marcar a hora do nascimento, ${ }^{30}$ a qual se levanta com o $12^{\circ}$ grau de Leão; ou a [estrela] brilhante de Coroa boreal, que se ergue com o $16^{\circ}$ grau de Libra - sendo cada uma delas do temperamento de Afrodite e de Hermes, caso surja na hora de nascimento, faz com que os assim nascidos sejam não apenas notáveis, favorecidos e estimados, mas também estudados, filosóficos, eloquentes, criativos, perspicazes, engenhosos, amantes da música, das artes, bem-dispostos, devotados ao prazer, aos luxos, alegres, também sagazes, intelectuais, inteligentes, suscetíveis de ter sucesso, de um modo geral enaltecidos pela virtude dos seus discursos, zelosos pelas virtudes, eloquentes, com discurso agradável, amáveis, complacentes quanto aos costumes, rápidos, críticos, generosos, por vezes promíscuos e instáveis face aos prazeres sexuais, se Ares estando a leste sobre a terra olhar para um desses lugares na hora do nascimento.

\footnotetext{
${ }^{26}$ Possivelmente Ptolemeu.

${ }^{27}$ Entenda-se 'essa leitura'.

${ }^{28}$ Tabela não remanescente.

${ }^{29}$ Austral.

${ }^{30}$ Cf. ஸ́робко́тос: 'hora de nascimento'.
} 
E se Ares estiver sobre um ponto cardeal, [os que nascerem] estão envolvidos em assuntos de foro legal ou impulsionados por desejo, especialmente estando assim colocado Ares $<$ Hermes $>$ na hora de nascimento. Contudo, se Afrodite e Ares, no lugar subterrâneo, observarem uma dessas [estrelas] na hora do nascimento, ou num ponto de ocaso, ${ }^{31}$ produzem opostos dos castos, religiosos, os que não conseguem atuar nos prazeres sensoriais, os que têm poucos filhos ou que geram apenas mulheres. De facto, resulta uma grande diferença a partir do ponto basilar ocupado por Afrodite e Ares. Se Cronos vir uma dessas 5 estrelas brilhantes na hora do nascimento, geram-se os conhecedores de medicina e prognóstico, muito versados em livros obscuros, livros ou iniciações. Mas se Zeus observar no levante uma das 5 estrelas brilhantes que referi, gera-se grande sorte, glória, poder, autoridade. Também existe uma diferença entre essas [estrelas]. A de Espiga faz hierofantas, honrados sacerdotes, filósofos, intérpretes de alguns mistérios, especialmente os nascidos na Grécia; e no tocante aos nascimentos femininos, produz sacerdotisas de Deméter, ou da Mãe dos deuses ou de Core ou de Ísis ou hierofantas, conhecedores de mistérios, ritos de iniciação, ou aqueles que evitam alguns alimentos são muito auxiliados pelos deuses. Caso se eleve ou culmine, a brilhante da Coroa boreal providencia estimados, magistrados, com direito a coroas, arcebispos, amigos de reis, os de corpo vigoroso, os tornados famosos e os amados por muitos. E se a brilhante do sul de Peixes se elevar, produz aqueles que têm poucos filhos, ou os têm tardiamente, ou apenas filhas (mulheres), ou não têm nenhuns, sobretudo eloquentes e bem parecidos.

Outrossim, se alguém nascer no levante do coração de Leão, que está no círculo do zodíaco no $20^{\circ}$ grau de Leão, ou na ascensão de Arcturo ou de Arctofílax, que se eleva no $30^{\circ}$ grau de Virgem, ou quando a [estrela] brilhante de Águia se ergue, a qual surge no $7^{\circ}$ grau de Capricórnio; ou ainda se alguém nascer quando Antares, que está no zodíaco sobre o $15^{\circ}$ grau de Escorpião, sendo cada uma delas ${ }^{32}$ a mistura de Zeus e de Ares, e elevando-se assim, ergue-se na hora favorável ao nascimento, ou ainda quando está a culminar, torna os que assim nascem estimados, comandantes, os que subjugam terras, cidades e povos, os que governam, homens temíveis, líderes, generais, dominantes, estimulados, independentes, loquazes, contenciosos, eficazes, inteligentes, viris, vitoriosos, flagelo dos inimigos, muito ricos, generosos e também pródigos, os que geralmente não morrem de uma boa morte. Nascem igualmente os com gosto na caça e em cavalos, e conhecedores ou donos de quadrúpedes.

De modo similar, se alguém nascer no levante da brilhante na extremidade da perna esquerda de Orion, o qual se ergue no $23^{\circ}$ grau de Touro; ou quando a [estrela] do meio das três, do cinturão dele, que se eleva no $30^{\circ}$ grau de Touro; ou com a do ombro direito do Auriga, que se ergue em conformidade com o $5^{\circ}$ grau de Gémeos; ou quando a do joelho de Sagitário se ergue, a qual no zodíaco fica sobre o $19^{\circ}$ grau do mesmo Sagitário; ou também quando a [estrela] brilhante na Górgona de Perseu, que se eleva em conformidade com o $2^{\circ}$

\footnotetext{
${ }^{31}$ Oeste.

${ }^{32}$ Entenda-se 'estrelas'.
} 
grau de Touro, sendo ao surgir mistura de Zeus e de Cronos, segundo referimos, fazem os nascidos assim ter muitas posses e muito ricos, adquirindo em diferentes regiões e cidades, amantes do campo e capazes de construir casas. Mas se a Lua visualizar uma das [estrelas] brilhantes de que falámos a elevar-se, ou a culminar no dia, [produz] virtuosos quanto ao carácter, os que respeitam os idosos, os de sentimentos nobres, generosos, tolerantes, sensíveis, amantes de entes queridos, prudentes, amigos dos seus parentes. E também, em particular quando a [estrela] sobre o joelho de Sagitário e aquela sobre o ombro direito do Auriga estão ou a erguer-se ou a culminar na perpendicular, faz aqueles que trabalham quadrúpedes ou carruagens, ou aqueles que têm o governo de cavalos ou a condução.

Se alguém nascer no levante de Cão, que aparece no $20^{\circ}$ grau de Gémeos, ou elevando-se sobre a cabeça do gémeo seguinte de Gémeos, que, no zodíaco, está sobre o $29^{\circ}$ grau de Gémeos, sendo [essas estrelas] uma mistura de Ares, e elevando-se na altura do nascimento, especialmente num nascimento noturno, fará os natos assim governantes, temíveis, ativos, impulsivos, independentes, irascíveis, teimosos, despóticos, líderes militares, notáveis; mas elevando-se <num $>$ nascimento diurno, produzem insolentes, cruéis, sem misericórdia, precipitados, vorazes, agitados, bêbedos. Porém, se culminam, [fazem], <na generalidade sensatos, misericordiosos $>$, e que certamente não têm uma bela morte.

De modo similar, se alguém nascer no levante da [estrela] boreal da garra de Escorpião, que se encontra no círculo zodiacal sobre o $25^{\circ}$ grau de Libra, ou que está na cabeça do gémeo anterior de Gémeos, sendo ambas do temperamento de Zeus e Hermes, e elevando-se, fazem os assim gerados com gosto em falar, eruditos, oradores, poetas, com gosto em música, beleza e < favor popular>, astutos, de boa constituição, capazes de muitas atividades, dignos, pios, religiosos, bons para negócios, muito conhecidos ou grandemente afortunados por receber presentes de ouro, prata e afins, os mais generosos face às desgraças, sobretudo nos nascimentos diurnos. É que, ao elevarem-se num nascimento noturno, fazem pretensos sábios, fanfarrões, treinados, ${ }^{33}$ intérpretes, instruídos, com boa memória, didáticos e de desejos puros.

Se surgir, no nascimento, a [estrela] no ombro dianteiro de Orion, que eleva no $27^{\circ}$ grau de Touro, ou Prócion, que se ergue no $27^{\circ}$ grau de Caranguejo, ou no ombro direito de Orion, que se ergue no $2^{\circ}$ grau de Gémeos, *** ou a comum de Cavalo e Andrómeda, que se ergue no $21^{\circ}$ grau de Peixes, tendo o temperamento de Ares e de Hermes, produzem os que têm assim, sobretudo nos nascimentos noturnos, comandantes, temíveis, enérgicos, versáteis, sábios, intrometidos, eloquentes, <de vozes penetrantes, enganadores, bem sucedidos $>$, não seduzíveis, mas perspicazes e insaciáveis nos desejos, sendo destruidores de meninos e meninas, perjuros. Erguendo-se nos nascimentos diurnos, fazem audazes, cruéis, arrependidos, falsos, ladrões, ímpios, sem amigos, impostores, os que cortejam o aplauso, insolentes, assassinos, falsificadores, feiticeiros, homicidas, e por vezes não têm um belo fim, sobretudo, como referimos, no nascimento noturno.

\footnotetext{
${ }^{33}$ Entenda-se 'hipócritas'.
} 
Similarmente, se na hora de nascimento encontrar a [estrela] a elevar-se sobre o pé direito de Centauro, a qual surge no $11^{\circ}$ grau de Libra, ou a última de Rio, que se ergue no $3^{\circ}$ grau de Carneiro, sendo ambas do temperamento de Zeus e de Afrodite, e elevando-se na hora de nascimento, tornam os assim nascidos puros, devotos do prazer, amantes do belo, da música, de presentes, pios, prudentes, amante de ouvir, bons no aconselhamento, de ânimo majestoso, no respeitável, de bons sentimentos, gracioso face aos prazeres sexuais e têm muito boa sorte com mulheres, apreciadores de fama, belos e bons, ${ }^{34}$ preferencialmente louros, de boa aparência e corpos delicados, especialmente se [as estrelas] olharem a Lua.

Se alguém nascer no levante da [estrela] brilhante da cauda de Leão, que está sobre o $27^{\circ}$ grau desse Leão; ou a [estrela] sobre os quadris dele, que está sobre o $17^{\circ}$ grau dele, ou ainda no levante da [estrela] brilhante de Hidra, que se ergue no $3^{\circ}$ grau de Leão, sendo do temperamento de Cronos e de Afrodite, quando estão a elevar-se na hora do nascimento, produzem os assim nascidos afortunados, com muitas posses, muito notáveis, emotivos, os que agem de modo abominável, os que falam suavemente, além disso amam dançar, os sinistros para os prazeres de amor, com o passar da idade adotam alguma prática religiosa, os que são reverenciados através de uma prática religiosa ou pelo autocontrole, os que se afastam de alguns alimentos, os que são entendidos em alguns livros ocultos; nascem amantes dos céus, os que têm olhos sobretudo cinzentos ou azulados, os que têm boa aparência.

$\mathrm{E}$ a [estrela] brilhante de Híades surgindo na hora do nascimento e ficando no círculo do zodíaco sobre o $15^{\circ}$ grau de Touro, tendo o temperamento de Ares e $<$ de $>$ Afrodite, e [estando] na casa de Afrodite, torna os nascidos assim bastante afortunados e ricos e aqueles que governam ou administram regiões e cidades. De facto, assim como esta estrela e a posição das Híades em todo o cosmos é a mais facilmente reconhecida por todos os homens e surge mais brilhante, assim os nascidos no levante ou hora do surgimento da [estrela] brilhante das Híades são os mais reputados, mais notórios, mais ricos de [todos] os outros homens. Isto ocorre quando está no mesmo grau da Lua, ${ }^{35}$ no levante ou na hora de nascimento. De facto, apenas esta estrela tem uma força dupla relativamente às outras estrelas, estando, na realidade, a brilhante de Antares a elevar-se, encontrando-se no mesmo diâmetro dela, sobre o $15^{\circ}$ grau de Escorpião e ambas [as estrelas] estão no círculo do zodíaco. Assim, a capacidade de, nas partes ocidentais e orientais e nas outras regiões, perluzir ilustres e grandes coisas.

E a própria [estrela de] Antares, encontrando-se no ponto basilar do poente, no local para matrimónio, tal como referimos no início, traz grande prosperidade e riqueza graças às mulheres. Com efeito, as mulheres dos que nascem assim são admiradas por todos e muito ricas, mas não longevas, pois de imediato Antares tem um ocaso, como dissemos, quando se encontra no local do casamento. E quando a [estrela] brilhante das Híades se ergue, possuindo a atividade produtiva de Ares e de Afrodite, faz os assim nascidos irados, bastante ardentes nos desejos e diferentes nos prazeres amorosos. Todavia, quando o lugar

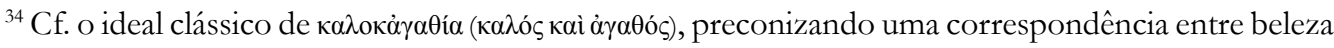
física e valor.

${ }^{35} \Sigma \varepsilon \lambda \eta \dot{v \eta, ~ " S e l e n e " . ~}$
} 
das Híades se eleva, marcando a hora do nascimento, do $11^{\circ}$ ao $15^{\circ}$ grau, faz por natureza os apaixonados por prazeres, os muito distintos e com lindos pescoços.

Tendo [nós] observado e trabalhado por tempo suficiente, encontrámos estas coisas, pois muitas vezes, não sendo nenhuma teoria encontrada boa nos nascimentos, e não havendo luzes no ponto cardeal, mas a declinar, [e] os benefícios não estarem num ponto basilar, vemos grandes e muito afortunados nascimentos, que não entenderíamos, sem as estrelas brilhantes a erguer-se com os pontos basilares ou a Lua. Ora, por este motivo, definimos a diferença e a ação das estrelas brilhantes e notórias, à exceção de uma de Canopo, uma vez que é muito meridional a sul e quase que não aparece nessas partes, tendo indagado na zona de Roma.

Então nós, seguindo o ensinamento do mui divino Ptolomeu, ousámos registar acerca da ação e da qualidade das 30 estrelas brilhantes. Para recordarmos aqueles que escreveram antes dele acerca das [fases] das estrelas não errantes e sobre o poder das que se elevam, proporcionámos isto: portanto, os Babilónios e os Caldeus foram talvez os primeiros a descobrir o conhecimento dos fenómenos, conforme soubemos dos nossos antepassados. Com efeito, Apolónio, o Míndio e Artemidoro anotam *** também escreveram a respeito delas Beroso e os que se seguiram. E os antecessores dos nossos Egípcios recordaram e fizeram previsões baseadas nelas. ${ }^{36} \mathrm{O}$ primeiro a surgir delas foi Hermes ${ }^{37}$ e escreveu, em Sobre os efeitos que os astros produzem no mundo, ${ }^{38}$ sobre a ascensão de Sírio $;{ }^{39}$ outrossim Necao, ${ }^{40}$ Cerásforo, ${ }^{41}$ Petósiris $^{42}$ e Nequepso ${ }^{43}$ e alguns outros escreveram em diferentes regiões acerca delas, em particular Timeu e Asclácio. Os que nasceram depois desses compiladores, observaram em muitos lugares diferentes quer muitas elevações, quer ocasos, quer outros sinais indicativos do que elas produziram em todo o tipo de região, e gravaram a atividade produtiva delas quase todos os dias: Meton, Apolinário, Euctemon em Atenas, Dositeu na Iónia, Calipo no Helesponto, Filipe no Peloponeso; Fócis, Lócris, Hiparto na Bitínia. E apresentam-se, em cada um dos referidos homens, tratados acerca $<$ das faculdades $>$ das estrelas não errantes $<\mathrm{e}>$ do produzido pela atividade delas. Então, se as misturas dos ares mudam uma certa quantidade, quando se elevam e fazem outras fases, conseguem agir mais sobre nós e causar grande prosperidade e adversidade, por vezes até a morte, quando os corpos, libertando-se se juntam a elas. Antíoco, Valente, Antígono, Heraisco e alguns outros redigiram muitas e diferentes coisas sobre o poder delas, como surge nos seus tratados. Serápio e Ptolomeu, nascido depois dele, fez predições sobre elas. Mas nenhum dos homens

\footnotetext{
${ }^{36}$ Entenda-se 'estrelas'.

${ }^{37}$ Ver egípcio Hermes Trismegisto ( $2^{\circ} / 3^{\circ}$ milénio a.C.).

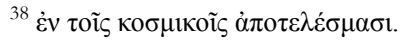

${ }^{39}$ Kvvós.

${ }^{40}$ Faraó egípcio.

${ }^{41}$ Astrólogo egípcio.

${ }^{42}$ Sacerdote, séc. II a.C.

${ }^{43}$ Astrólogo egípcio.
} 
que referi traduziu os posicionamentos astronómicos que elas agora têm, nem o produzido pela mistura delas.

Portanto, tendo [nós] registado acerca do poder específico e atividade das estrelas não errantes e brilhantes, e tendo explicado a partir de princípios naturais, razoavelmente, submeteremos os poderes das estrelas falhas, assim como o que elas produzem.

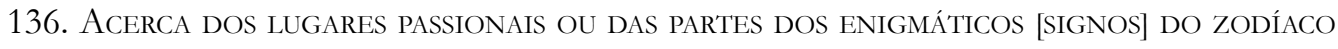
CARNEIRO, TOURO, LEÃO, CAPRICÓRNIO

Existem também outros lugares no círculo do zodíaco, em certos membros [das figuras] do zodíaco, onde não existem [estrelas] de primeira nem de segunda magnitude, mas inferior, e tendo, em particular, poder suficiente e quase inalterável, a observação realiza-se em relação à parte emotiva da alma e sobre as lesões do corpo. De facto, primeiramente, incorrem nos infortúnios anímicos e nas paixões quantos homens e mulheres nascem quando as partes dianteiras ou a face de Escorpião surgem ou regulamentam a hora de nascimento no $13^{\circ}$ e $14^{\circ}$ graus, e quando as partes posteriores em torno dos $25^{\circ}, 26^{\circ}, 27^{\circ}$ e $28^{\circ}$ graus, e as Híades ou a face do Touro nos $12^{\circ}, 13^{\circ}, 14^{\circ}$ e $15^{\circ}$ graus, e ainda as partes posteriores de Leão, desde o $25^{\circ}$ grau ao $30^{\circ}$ grau, e a face ou focinho do Capricórnio em redor do $11^{\circ}$ e $12^{\circ}$ graus. De facto, estes, quando marcam a hora de nascimento e se elevam, conforme referimos, fazem os assim nascidos comportar-se de modo licencioso não apenas para com as mulheres, mas também para com as crianças e deliciar-se com os prazeres para além da natureza ou com mulheres sensuais, sujeitas a descarga ${ }^{44}$ vis ou face às mulheres assim nascidas continuarem de modo vergonhoso ou terem prazer com as obscenidades de homens. Tendo, portanto, homens e mulheres a mente perturbada a partir do curso inalterável das estrelas para a união sexual, falham através da apetência do desejo, ao usarem de modo diferente essas coisas e os prazeres além do natural. Mas se a estrela de Afrodite se encontrar nestes mesmos enigmáticos signos do zodíaco, Carneiro, Touro, Leão ou Capricórnio, ao ser observado por Ares ou Cronos e, conforme referimos, estando nos membros ou lugares dos signos do zodíaco, que desviam os que assim nascem com paixões vergonhosas. Se de forma escondida ou evidente, mostram-se pelo levante e ocaso das estrelas que produzem isso, digo, Afrodite e Ares, ou Afrodite [f. 156 ${ }^{\mathrm{v}}$ ] e Cronos, particularmente quando são configuradas numa maneira contrária, exibem as paixões muito manifestas e notáveis. Na realidade, não acontece de outra forma usarem-se prazeres contra a natureza, se primeiramente não completarem o desejo da paixão e a necessidade do demónio, como ouvir desejos de forma nefasta, acarretam que alguns tenham complicações, enganos, perdas, inimizades e condenação, se a [estrela] de Zeus tendo observado Afrodite, não suprima uma parte dos males. Ou, pelo contrário, estão ocultas do Sol ou no ocaso, e sobretudo de Afrodite, abri(gam) segredos, a proteção de alguém, ou os infortúnios dos

${ }^{44}$ Entenda-se 'menstruadas'. 
que escutam a licenciosidade ou os desejos, mostram muito a obscenidade delas. E indicam quando as mulheres tríbades ${ }^{45}$ vão obscenamente aos homens. Pois, por necessidade, as praticamente cegas nos desejos injuriam o intelecto. Ora, uma vez que eles [desejos] brotam sem controle acerca das paixões, quer o esvaziar dos desejos, quer o comportamento com absoluta licenciosidade geram-se. Entendemos o poder disso pela mistura das estrelas. E se Ares juntamente com Afrodite forem ambos vistos de manhã por [estrelas] maléficas, fazem os assim nascidos totalmente comportarem-se vergonhosamente com toda a imprudência, de modo visível. E frequentemente esses são licenciosos não apenas para com homens ou mulheres, mas também para com animais irracionais, por exemplo, quadrúpedes, ou outros. Mas se a [estrela] de Afrodite se encontrar sobre o ponto basilar ou a oeste, observada por Ares ou Cronos, ou o próprio Ares se encontrar assim, nas partes dos ocasos, e principalmente nos signos do zodíaco servis, conforme mencionei, cria castrados, eunucos ou improdutivos ou os que se abstêm de prazeres sexuais devido a serviço religioso, os que temem os deuses e os que são culpáveis nos prazeres sexuais.

\section{SOBRE OS GRAUS INJURIOSOS OU PRAZERES QUE SÃO PREJUDICIAIS PARA OS OLHOS}

Muitos dos anteriores a nós indicaram que os astros destrutivos, enquadrando as luzes ou estando em conjunção com elas nos graus de ascensão ou nos signos do zodíaco ferem os olhos. E sobretudo se Cronos num nascimento noturno observa a Lua minguante assim, ou então Ares, colocado num [nascimento] diurno, estando ela ${ }^{46}$ a aumentar. $\mathrm{Na}$ realidade, unem-se ou opõem-se ou esquadram-se e também quando estando eles ${ }^{47}$ sobre um ponto basilar, as luzes retiram-se. Cronos, todavia, traz dano, em conformidade com o que precede, faz assim aos [olhos] através de cataratas ou resfriamento aos que sofrem disso. Ares causa cegueiras a partir de um golpe, pancada, corrente de ferro, fogo, fluxo de calor. Mas quando está configurado com Hermes e a olhar o Sol ou a Lua, conforme se indica, [causa cegueira] nas escolas ou ginásios, ou por ataques de criminosos.

$\mathrm{E}$ alguns antigos expõem essas coisas, que nós mesmos confirmamos. Porém, existem também outros lugares dos membros dos signos do zodíaco ${ }^{48}$ que têm grupos nublosos tipo nuvem compostos de estrelas pequenas e quase invisíveis, criadas para observação singular. Se a Lua estiver sobre elas quando sob a união amarra e especialmente tendo mergulhado ou surgido no horóscopo, ou também $<_{\mathrm{O}}>\mathrm{Sol}^{49}$ for encontrado assim, e sem os malefícios

\footnotetext{
${ }^{45}$ Ver tríbades, o mesmo equivale a dizer mulheres bissexuais, contudo com preferências lésbicas. Cf. Parménides (fr. B18.231-240) menciona um incidente inibidor de uma 'correta união dos elementos de proveniência masculina e feminina no momento concetivo, donde as atitudes efeminadas em homens, supraviris em mulheres (cf. Sen. Ep. 20.122.7) e o surgimento de tríbades. Autores como Muret (1587, p. 221-22) consideram Safo como um exemplo de tríbade.

${ }^{46}$ Entenda-se 'Lua'.

${ }^{47}$ Entenda-se 'astros destrutivos'.

${ }^{48}$ Zoidia.

${ }^{49}$ Hélios.
} 
de olhar as estrelas, ferem os olhos e turvam-nos. E em particular, acerca da nuvenzinha de Caranguejo, que está a partir do $11^{\circ}$ grau até ao $14^{\circ}$ grau; e sobre as Plêiades de Touro, a partir do $4^{\circ}$ grau até ao $6^{\circ}$; e da seta de Sagitário, que fica no $7^{\circ}$ grau dele; e do nubloso do olho de Sagitário, que fica o $18^{\circ}$ grau dele, ou também da ponta da espada de Escorpião, que fica no $27^{\circ}$ grau dele, e das jubas do sul de Leão, no $27^{\circ}$ grau, sobre a de norte, no $30^{\circ}$ grau de Virgem, no jarro de Aquário, do $17^{\circ}$ grau ao $18^{\circ}$, no ferrão e Capricórnio, nos $2<5^{\circ}>$ e $28^{\circ}$ graus. Se Cronos ou Ares observarem a Lua ou o Sol, estando nesses lugares e um desses [destruidores] se encontrar nos graus que referi, e estiver embaraçado nas luzes, em especial localizado sobre o local de ocaso ou no de levante, os assim nascidos magoam os olhos permanentemente. Se nem Zeus nem Afrodite olharem as estrelas que criam o motivo ou os locais e decanos que expusemos na tabela, como também comporta o livro de Hermes, no qual escreveu o maior número de coisas iatromatemáticas. Quando os destruidores estão sobre os próprios decanos, enviam sofrimentos e ferimentos relativamente àquelas partes que cada um $<$ dos $>$ decanos governa, sobretudo se na génese Cronos dominar o local perversos nos nascimentos noturnos e Ares no produto diurno. É que assim fazem os danos evidentes e os sofrimentos difíceis de eliminar.

Mas quando os [destruidores] que enviam sofrimentos prevalecem ou irradiam pelos benéficos, digo Zeus, Afrodite ou Hermes, fazem um protetor sem reprovação, e os sofrimentos moderados e facilmente aliviados, e por vezes são fáceis de eliminar, especialmente se algum dos benéficos, estando no levante, olhar para os locais que produzem a causa. Com efeito, a [estrela] de Zeus costuma esconder as enfermidades através da abundância de riqueza e da assistência humana, e consola os sofrimentos. E quando Hermes, a par de Zeus, está a observar de qualquer forma os decanos ou lugares que referi, removem ou mitigam os males com a ajuda de médicos e da conjunção de drogas. Quando <a $>$ [estrela] de Afrodite matutina observar os lugares responsáveis, faz as enfermidades não desfigurativas e cura os sofrimentos através da intervenção divina ou de oráculos, amuletos, sacrifícios expiatórios, ou de algumas preces. E tendo a [estrela] de Hermes sozinha observado uma estrela maléfica além do conjunto, encontrando-se bem posicionada, traz, para os que têm assim, certos auxílios através das enfermidades ou dos sofrimentos.

Em particular, alguns signos do zodíaco e das estrelas não errantes, encontrandose no grau lugar dos deuses ou no lugar subterrâneo, ou erguendo-se, trazem para os que nascem grandes auxílios através das aparições dos deuses ou através dos sonhos.

E quando Escorpião se encontra assim, especialmente no $27^{\circ}$ grau, onde está a [estrela] brilhante de Ofiúco, cura os que nascem assim através da manifestação de Asclépio ou Serapis ou do seu poder, ou da amizade dos médicos. E quando a [estrela] Espiga, que está no $28^{\circ}$ grau de Virgem se encontra assim, faz saúde através da exposição da Mãe dos Deuses, de Core, ou de Afrodite. E quando a [estrela] sobre a cabeça do gémeo precedente de Gémeos, que está no $26^{\circ}$ grau, assim, encontrando-se 7 graus antes do lugar dos deuses ou no ponto basilar subterrâneo ou no levante, causa auxílios, através de Hermes, Telésforo ou Apolo. E quando a [estrela] na cabeça do gémeo seguinte de Gémeos, que está sobre $29^{\circ}$ grau deles, se encontra assim, e especialmente nos nascimentos noturnos, traz manifestação 
ou assistência através de Héracles, ou <nos [nascimentos] diurnos>, através dos Dióscoros. E quando a [estrela] brilhante de $\mathrm{CãO}^{50}$ se ergue no $20^{\circ}$ grau de Gémeos e se encontra nos sítios que mencionei, e em particular nos nascimentos noturnos, traz assistências ou manifestações de Hécate, ou do próprio Ares, ou de Anúbis ou até através de oferendas ou do fogo, ou do sangue ou de sacrifícios expiatórios. E a [estrela] de Lira, através de Apolo e Hermes. E as [estrelas] sobre os chifres de Capricórnio e as Hedi ${ }^{51}$ e Cabra, quando se encontram nos locais que mencionei, acarretam auxílio ou manifestação através de Pã ou através de Hermes, especialmente se algum dos benéficos observar os locais referidos.

Cada um dos planetas encontrando-se de acordo com a sua própria natureza sobre os lugares mencionados, e em particular os benéficos, proporciona auxílios e aparições, segundo a própria natureza poderes. Cronos, no nascimento diurno, traz o seu próprio auxílio ou também o da visão através de Hades e Posídon e traz tratamento a partir do contrário das próprias plantas e de outras coisas. Porém, quando está mal posicionada num nascimento noturno, acarreta, através de feições mortos ou de sinais $<$ de mulheres $>$ ou do temor dos deuses, e Ares traz coisas ${ }^{52}$ próprias da sua natureza, benéficos na noite, temíveis, opostos e prejudiciais para os nascidos no dia.

\section{REFERÊNCIAS}

ALLEN, R. Star Names, Their Lore and Meaning. New-York: Dover Publications, 1963.

BARTON, T. Ancient astrology. London; New-York: Routledge, 1994.

BEZZA, G. Précis d'historiographie de l'astrologie: Babylone, Egypte, Grèce. Turnhout: Brepols, 2002.

BOUCHÉ-LECLERCQ, A. Histoire de la divination dans l'Antiquité. Divination hellénique et divination italique. Paris: Leroux, 1899.

BROWN, D. Mesopotamian Planetary Astronomy-astrology. Groningen: STYX, 2000.

CUMONT, F.; BOLL, F. Catalogus Codicum Astrologorum Graecorum. Partem Priorem, V/1. Bruxellis: in Aedibus Heinrich Lamertin, 1904.

HAND, R. (Ed.). Anonymous of 379. Berkeley Springs: The Golden Hind Press, 1993.

LINDSAY, J. Origins of Astrology. London: Frederick Muller, 1971.

MAASS, E. Analecta Eratosthenica v. 3, v. 6. Berlin: Weidmannsche Buchhandlung, Philologische Untersuchungen, 1883.

MORRIS, I.; POWELL, B. (Eds.). A New Companion to Homer. Leiden: Brill, 1997.

MURET, M. Variarum lectionum. Antuerpiae: apud Christophrum Platinum, 1587.

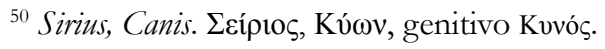

${ }^{51}$ Cf. Eratóstenes, Cat.13. Ver Eta e Zeta Aurigae.

${ }^{52}$ Entenda-se 'assistências ou manifestações'.
} 
NAGY, G. Homeric Questions. Austin: University of Texas Press, 1996.

NEWTON, R. The Crime of Claudius Ptolemy. Baltimore; London: The John Hopkins University Press, 1978.

NIKULA, R. Astrologian Historia. Helsinki: Ursa, 1993.

PÀMIAS I MASSANA, J.; ZUCKER, A. Ératosthène de Cyrène. Paris: Les Belles Lettres, 2013.

PÉREZ JIMÉNEZ, A. (Ed.). Astronomía y Astrologia: de los orígenes al Renacimiento. Madrid: Ediciones Clásicas, 1994. 